\title{
Discussion on Current Teaching Situation of MOOC-A Case Study of Wuhan Donghu University

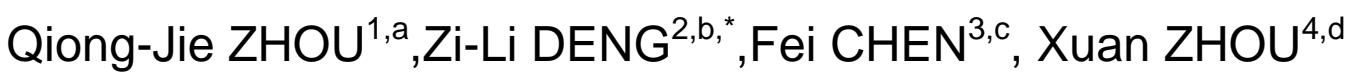 \\ 1,2,3,4 Wuhan Donghu University, 301wenhua Road,ngxia District, \\ Wuhan, 430212,Hubei,China
}

akatharine7878@163.com, ${ }^{\mathrm{b}}$ 353460706@qq.com, ${ }^{\mathrm{c}} 783722344 @ q q . c o m,{ }^{\mathrm{d}} 215746122 @ q q . c o m$

${ }^{\star}$ Corresponding author

Key words:MOOC, College education, Teaching mode, Internet + education.

\begin{abstract}
Massive open online courses (MOOC) have triggered a lively discussion of the community for their diversified resources, large-scale and open features. Starting from the actual research data of domestic universities, this paper analyzes the actual use of MOOC in depth from various aspects,explores the issues in the practical use of MOOC worthy of our attention, and puts forward reasonable and feasible improving recommendations.
\end{abstract}

\section{Introduction}

\section{MOOC Wave Coming}

Advent of MOOC In 2012, a new type of teaching model - MOOC model, appeared in the traditional teaching field like a hurricane, and a large number of MOOC learning courses emerged.Many well-known universities in the world have set uponline learning platforms, and tried this new teaching model. Thus, 2012 is even called "the year of the MOOC" by the media.It is even known as "themost profound technological change in the field of higher education in the past 500 years", which indicates that the impact of MOOC in the field of education is extraordinary.

At present, the state puts forward the action project of "Internet +", to promote the integration development of information technology and education field. Nobody would feel strange to "MOOC" which rises in response to the proper time and conditions, even if they may not understand. In the search engine of Baidu, over 6.3 millioninformation records involving the key word of "MOOC" can be searched.Baidu Encyclopedia explains "MOOC" as massive open online courses.

\section{Urgent Need of Applied and Technical Colleges and Universities}

In response to the demands of "promoting the characteristics of colleges and universities,establishing university classification system and implementing classified management" and "establishing modern vocational education system" proposed by Outline of National Medium and Long-term Education Reform and Development Plan (2010-2020),more than 600 of China's 1200 national institutions of higher education willtransform into applied and technical colleges and universities, which means that the proportion ofChina's colleges and universitiestrainingskilled personnelwill increase substantially.These applied technical colleges and universities are the backbone force of cultivating professional talents, but because of career development limitations, lack of scientific research atmosphere and other reasons,facultystrength lags behind that oftop universities.This situation will directly affect the quality of curriculum construction in these colleges and universities, and hinder the cultivation of outstanding technical personnel.Therefore, it can be said that the requirements of applied and technical colleges and universities forexcellenteducational resources have become increasingly stronger.

\section{Summary of Current Situation}

The Ministry of Education's Views on Strengthening the Application and Management of Online 
Open Courses Construction in Colleges and Universities (High Education [2015] No. 3) can be regarded as a programmatic document on na's curriculum reform in higher education during the 13th Five-Year Plan period. This document requires colleges and universities to build online open courses and public service platform, to strengthencurriculum construction and public service platform's operation and regulation, to promote the in-depth integration of information technology andteaching, promote the application and sharing of high-quality education resources, and comprehensively improve teaching qualitybased on national conditions.

Wuhan Donghu University, as one of the first batch of applied and technical colleges and universities in China, actively responded to the call of policies and introduced MOOC to assist teaching in 2014, to improve the teaching quality of school students and optimize the educational resources of school.So far, Wuhan Donghu University has introduced MOOC for nearly two years, and has achievedobvious effects.However, as MOOC is a new thing in the field of education, its application in practical teachingwill inevitably have some problems because of its own shortcomings and its integration with actual teaching.

According to this situation, the research team selected 42 MOOC learners majoring in human resources management, logistics management, tourism management, computer information and technology, accounting and auditing in Wuhan Donghu University, used questionnaires and semi-structured interviews to research their basic information, learning situation, learning behavior characteristics, platform function preferences, learning experience andproblemsindepth.The results of the survey show that $83 \%$ of respondents select 3 pointsor even below when they rate their comprehensive rating scores of learning status and learning degree(5 levels ranging from 1 to 5 points).This shows that the efficiency of current MOOC learning model canstill be greatly enhanced. Following three points for the low learning efficiency of the learners can be drawn by analyzing the survey results.

(1) The initiative to use MOOC learning model needs to be strengthened.

(2) The utilization rate of the function and resource of MOOC is low.

(3) The integration degree of online and offline courses is not good.

\section{Analysis on Questionnaire Data}

The following part conducts specific analysis on above summary pointsbased on the data of questionnaire.

\section{MOOC Learning Initiative}

(1) Reason for using MOOC.According to the questionnaire results, $45.2 \%$ of the respondents chose the school's hard rules, indicating that many studentslack of understandingon the MOOC, this new way of learning, and its advantages .

(2) Attractiveness of MOOC itself. For students of applied and technical colleges and universities, their expectations for learning objectives, practicality and profession are stronger.According to the survey data mapping (Figure 1-1), more than $90 \%$ of the respondents said thatthe release of MOOC certificate of completion would improve their learning enthusiasm. 


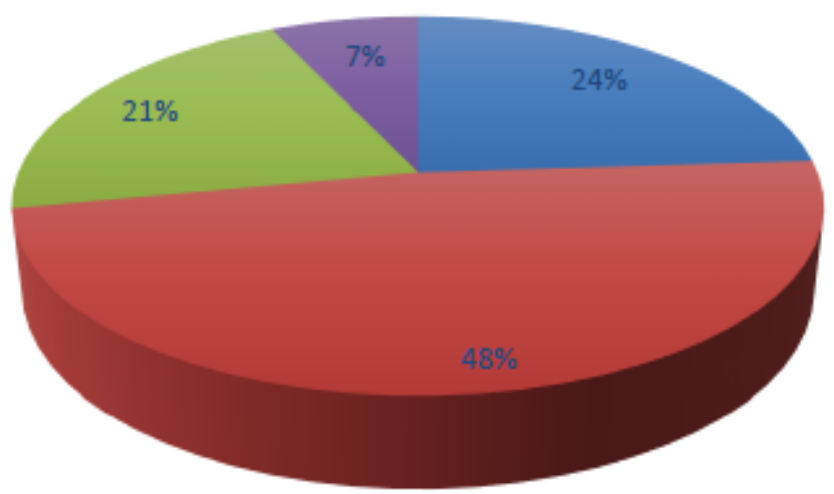

a. Have great impact, and will study actively $24 \%$

B.Have relatively great impact, and willing to study $48 \%$

ac. Have a certain impact $21 \%$

D. Have no impact on learning initiative $7 \%$

Fig. 1-1

(3) Impact of initial learning experience.Thorndike, an American psychologist, argues that human learning behavior and its effect are regular, andthe effect law of his three major learning laws points out that if an action follows a content change in the context, the possibility ofrepetition of the action will increasein a similar context, but if it follows a discontent change, the possibility of repetition of the action will decrease. In other words, if a person can get a good learning experience in the initial learning process, his/her attention and determinationof further study can be enhanced, thus achieving the optimal learning results, otherwise negative effect would be generated.According to the theory ofThorndike's effect law, we set up a question in the questionnaire: why are you unable to focus on studying in the process of learning MOOC for the first time?(as shown in Figure 1-2) The reasons accounted for the largest proportion in the survey results are: $50 \%$ of the respondents'learning satisfactions are affected because they are not interested in the course content; $21.43 \%$ of the respondents are affected because the surrounding learning environment is not good.A variety of different reasons lead to the low satisfaction degree of learners in the initial use of MOOC, thus having a greater negative impact on their later learning initiative .

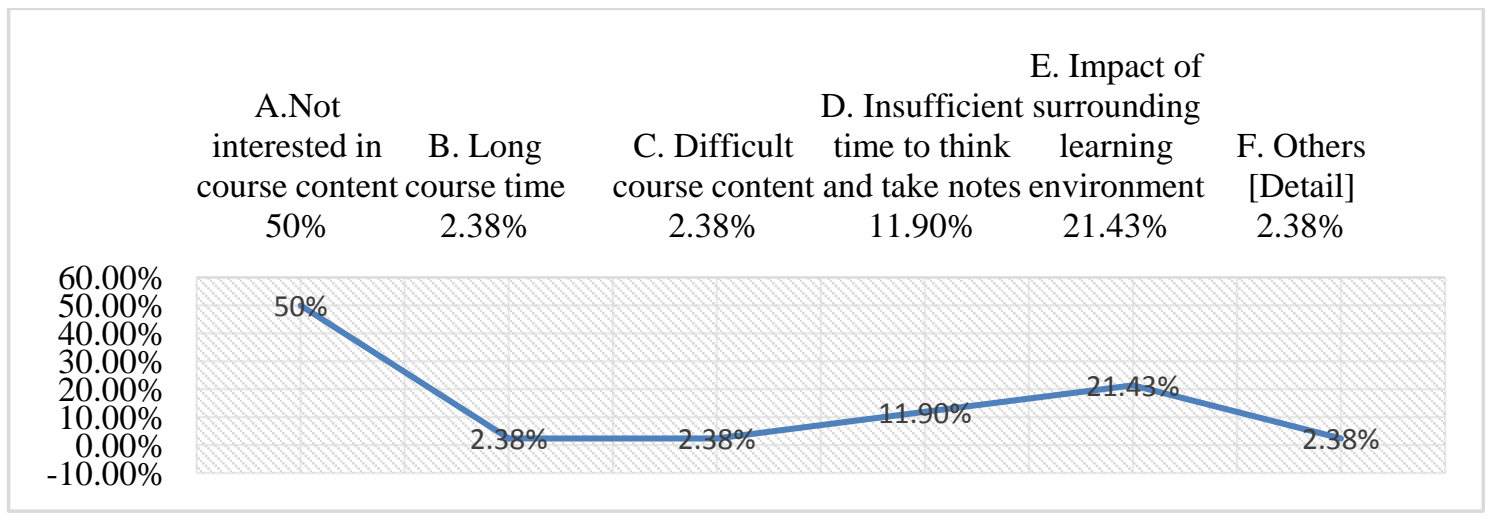

Fig. 1-2

\section{Function and Resource Utilization of MOOC}

As a learning platform, MOOC has rich and numerous learning resources, and is also essential for timely solving students' problems as well as providing communication channels between teachers and students and between students and students. Current MOOC learning platform hasa variety of 
different functions to meet the above needs of its learners. The MOOC platform, which is introduced by Wuhan Donghu University, is taken as an example, and the mainstream communication functions of current MOOC platformdeveloped for learners are online asking of community,real-time barrage of video, mutual evaluation of partners and so on.Specific analysis is conducted by combining research-related data.

In the questionnaire, the research team specifically designed the options for the above mentionedmajor functions, but the results are not satisfactory. Only $33.33 \%$ of respondents said they would leave a message in the community when they had problems in MOOC learning project, and $47.62 \%$ of them said they had used the barrage function to help other learners to solveproblems in the process of watching video.The utilization rate of the function of mutual evaluation is evenas low as $14.29 \%$, and even $35.71 \%$ of the respondents said they hadnever heard of this function. It comprehensivelyshows that the learner'sutilization rate of the function and resources of current MOOC mode is too low, and the best case is less than 50\%.

In response to this situation, the research team conducts semi-structured interviews with three studentsthroughrandom selection, and explores the specific reasons for the low utilization rate indepth. And the following reasons can be drawn through summarizing the views of the three respondents.

(1) The online time of professional teacheris short in community message, the answer is not timely, the communication between teachers and students is difficult, and the efficiency is low.

(2) The entertainment feature of barrage function is even greater than the communication feature, and speeches are numerous, complex and diverse, whichcauses great obstacles for learners who really need to communicate forsolving problems.

(3) The function of mutual evaluationis designed for learnersto encourage each other,to achieve the role of improving learning efficiency. However, due to the lack of publicity and guidance for this function, the utilization rate of this function is less than $20 \%$.

In summary, it can be said that the low utilization rate of learning resources and functionsequipped in MOOC learning platformis one of the main reasonscausingthe poor learning efficiency of MOOC learners

\section{Poor Integration Degree of Online and Offline Courses}

As is shown in Figure 1, in the survey, we dividedthe integrationdegree of offline courses to online courses into two aspects to illustrate: first, for the technical problems learners encountered in the process of MOOC learning, whether the teacher of offline courses can help solve them timely; second, whether the offline courses can help solve the knowledge-related problems that the learners encounteredtimely.

According to Figure 1-3, we can easily find that the integration degree of online and offline courses in technical issues is superior to that of knowledge-related problems.Even in the aspect of thetechnical problems with better integration degree, most of the respondents stillselected the choices of relatively consistent and uncertain, which shows thatthe integration degree of online and offline courses of current MOOC mode can still be greatly improved. 
- In course learning, the technical problems can be solved timely.

Offline courses have substantial help for my learning.

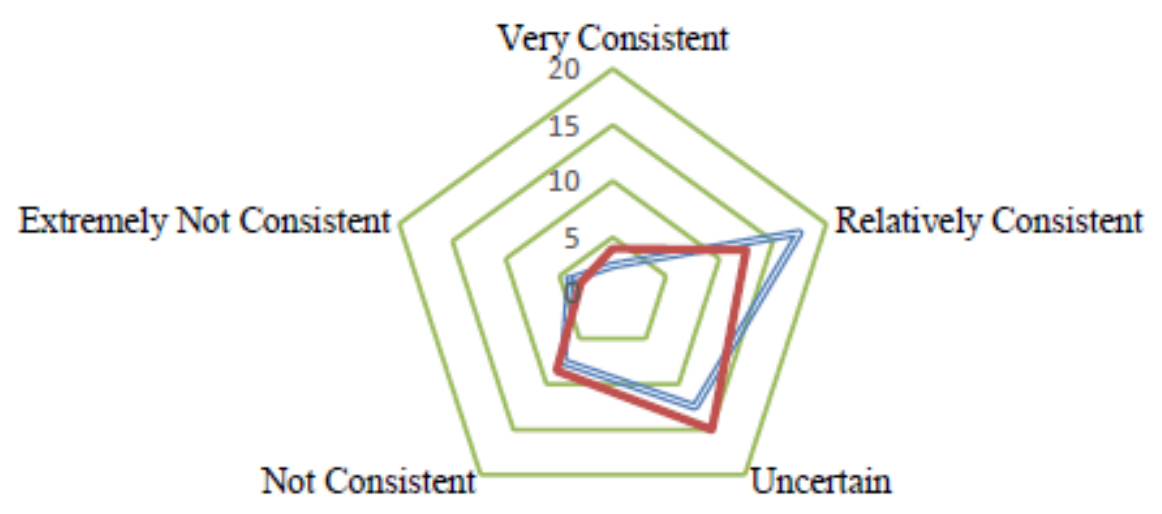

Fig. 1-3

\section{Improvement Measures}

Based on the analysis of all the data and interview contents, we propose specific improvement measures for the three root causes of the poor learning efficiency of MOOC learners based on the MOOC teaching practice of Wuhan Donghu University.

\section{Improving the Initiative of MOOC Learners}

According to the problems reflected by questionnaire data, the improvement can be conducted from the following aspects.

Firstly, Chinese universities have joined the construction practice of MOOC since the beginning of 2013, so MOOC is a new type of learning model for both Chinese university students and autonomous learners in society. For this new thing, Chinese major universities have the obligation to unitevarious social forces to promote the MOOCthrough various channels, to make it really becomethe gospel of all the people who havelearning needs.

Secondly,one of the advantages of MOOC is that it can span the limitations of time and space, and its learners can actively browse courses of various universities at home and abroad, to expand their learning resources.In practice teaching, due to various problems in cost and management, the colleges and universities will selectively purchase courses within the limited scopefor their students.For example, Wuhan Donghu University selectively purchased Poetry Appreciation, Speech and Eloquence,Entrepreneurial Guidance for College Students and several other courses when introducing MOOC teaching, and the interest and demand of students majoring in different majors for the courses selected by the school are not the same.This phenomenon limits the advantages of MOOC itselfto some extent, and reduces its attractiveness. As the saying goes, it is difficult to cater for all tastes, and for the university, the demand for diversified and targeted curriculumis a necessity.Taking into account the introduction fee of MOOC courses and university curriculum management, conducting research on courses demand in advancewill be a reasonable and feasible compromise.Understanding the learners' interests and needs and focusing on the choicecan reasonably meet different demands in a wide range.

Thirdly, the learning environment can also be improved.Another big advantage of MOOC is that as long as there are networking conditions, you can choose the location and time to learn by yourself.However, this advantage also has some hidden defects while bringing convenience for the learners.For example, with the loss of time and space control and guidance, learners' learning behaviors are all controlled by self-consciousness; a variety of interferencewill be inevitable in unrestricted learning places. This will reduce the learner's learning efficiency to a certain extent.Colleges and universities introducing MOOC coursescan set places with ideal learning 
environment, such as computer room, study room and library, as special “MOOC study area”.In this way, the ideal learning environment helps to improve learner's learning efficiency, and learners can also create a good learning environment in the learning area, in turn, to promote their learningFinally, through survey data, we found that $90 \%$ of respondents said that issuing a certificate would improve their learning initiative.Thus, colleges and universities and even social training organizations canimplement the "learning-assessment-certificate identification" model to motivate learners by uniting MOOC courses merchant and professional certificate issuing agency, in order to improve learner's learning efficiency and promoteMOOC.

\section{Low Utilization Rate of the Resources and Functions of MOOC Platform}

Starting from the objective reasons, the most important thing is to improve the operation model of the current functions of MOOC, to make it more personalized.For example, for the problem proposed by respondents that the questions left in the community cannot be timely answered,the following methods can be applied for improvement.

(1)A self-assistant Q \& A area can be set for each course, and the teacher or assistant sets the problems that students may have and the key and difficult knowledge points in advance, to designdetailed explanation area or guiding, gradual answering link.

(2) During the setting period of the course, a fixed time can also be set for the online interaction between teachers and studentsfrom time to time.The setting of this link shouldinform the learnersin advance through e-mail, text messages and other forms.

(3) After school, popular media like QQ, WeChat and microblogcan be used to connect the learners of the same course at different regionstogether, to supplement the shortcoming of inconvenient message leaving in the community, so that learners can communicate with each other easier.

The inconvenience of communication between teachers and students, students and studentshas always been one of the biggest defects inMOOC learning mode.If the functions of current MOOC can be designed humanely, and the convenience of the network platform can be effectively used, to reduce the impact of this defect to a minimum,the learner's learning efficiency can be improved greatly.

\section{Advantages of MOOC Learning Mode}

The original intention of setting offline courses for online courses is to supplement online courses, improve the inconvenience of communication and enhance the constraints on the learners. If the offline coursescannot fit well with the online courses, or cannoteffectively assiststudents in learning, they are useless. Only when they completely integrate with online courses can the advantages of MOOC learning mode be fully played. For this point, the setting of offline courses should emphasize the following points.

Firstly, the instructor of the MOOC course should conduct training of the same model forthe teachers ofoffline courses, so that they can use appropriate teaching method to teach the course content precisely in the offline class, to improve the courses' fitting withMOOC course.

Secondly, the curriculum setting should also follow a model, such as course duration, interval, teaching place and so on, to standardize all aspects, support MOOC online courses to the maximum degree, and achieve a good auxiliary purpose.

Finally, the offline courses can also play a certain supervising and reminding role in learners' learning, so that offline coursesshould be effectively used tomake up the defect that the restriction from MOOC course on the learners is low.It is worth noting that the information of the limited number of offline courses shouldinform learners in advance to prevent error and negligence.

All of the above are based on the research data ofthe actual use condition of MOOC course in Wuhan Donghu University, and feasible improvement measures are summarized by integrating the advice and recommendations of several respondents and teachers of offline courses. 


\section{Summary}

In today's society,“Internet +" strategy has profoundly influenced various fields including communications, transportation, finance and business, and education is no exception.MOOC, as a new thing generated in the field of education under the Internet thinking, has gradually demonstrated its unparalleled advantagesin the practical application. However, we still need to improve it in the application process, so that it can better benefit the community.

\section{Acknowledgement}

This research was financially supported byWuhan Donghu University Undergraduate research project [2015] Document, the title is Discussion on Current Teaching Model of MOOC-A Case Study of Wuhan Donghu University.

\section{References}

[1] Li Hua, Gong Yi, Ji Juan, Tan Mingjie, Fang Jiaming. Framework Design of Learning Management System for MOOC [J]. Modern Distance Education Research, 2013 (03)

[2] Jiang Lin, Han Xibin, Cheng Jiangang. Study on the Characteristics of MOOCs Learners and Learning Effect[J]. China Educational Technology, 2013 (11)

[3] Wu Minghua. Emergence of Massive Open Online Courses[J]. World Affairs, 2013 (14)

[4] Hao Dan. MOOC: Subversion and Innovation - Summary of the Fourth "Youth Scholar Forum of China Distance Education” [N]. Distance Education in China: 2013 (11)

[5] Laura Pappano . The Year of the MOOC[OL].

http://www.nytimes.com/2012/11/04/education/edlife/massive-open-online-courses-are-multiplying -at-a-rapid-pace.html?pagewanted=all\&_r=0.

[6] Quoted from Baidu Encyclopedia

[7] The resources are from http://www.moe.edu.cn/publicfiles/business/htmlfiles/moe/moe_838/201008/93704.html

[8] This concept is first put forward by Thorndike in the book, Educational Psychology (1903), which are known as three learning theories of Thorndike along with practice law and preparation law.

[9] Barrage, a popular Chinese word, refers to the phenomenon that many comments appear simultaneously in the form of captions.(Baidu Encyclopedia) 